\title{
Induction chemotherapy, surgical resection, and high-dose chemotherapy for mediastinal nonseminomatous germ-cell tumor
}

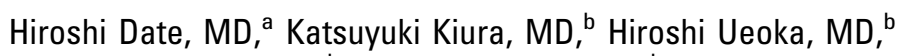
Masahiro Tabata, MD, ${ }^{\mathrm{b}}$ Katsuyuki Hotta, MD, ${ }^{\mathrm{b}}$ Hideki Katayama, MD, ${ }^{\mathrm{b}}$ Itaru Kataoka, MD, and Mitsune Tanimoto, MD, ${ }^{\mathrm{b}}$ Okayama, Japan

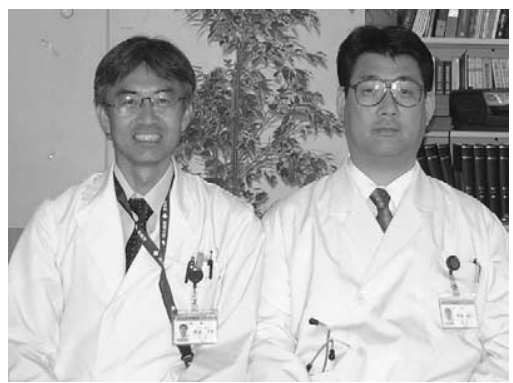

Drs Date and Kiura
M ediastinal nonseminomatous germ-cell tumor (NSGCT) has a very poor prognosis. ${ }^{1}$ We report 3 cases of mediastinal NSGCT successfully treated with induction chemotherapy, radical surgical intervention, and high-dose chemotherapy (HDCT) supported by autologous peripheral blood stem-cell transplantation (PBSCT).

\section{Clinical Summary}

Three young men with large mediastinal NSGCTs met the requirements to enter the study (Figure 1 and Table 1). All patients were given pathologic diagnoses of NSGCT on the basis of needle biopsy and showed increased alpha-fetoprotein (AFP) levels. Testicular ultrasonography was performed to rule out testicular primaries.

Planned treatment began with induction chemotherapy consisting of cisplatin, etoposide, and bleomycin. Cisplatin was administered at a dose of $20 \mathrm{mg} \cdot \mathrm{m}^{-2}$ on days 1 through 5 , etoposide was administered at a dose of $100 \mathrm{mg} \cdot \mathrm{m}^{-2}$ on days 1 through 5 , and bleomycin was administered at a dose of $20 \mathrm{mg} \cdot \mathrm{m}^{-2}$ on days 1, 8, and 15. The bleomycin, etoposide, and cisplatin (BEP) induction chemotherapy was delivered for 4 cycles at 2-week intervals. During hematologic recovery after the third or fourth cycle of the induction chemotherapy, peripheral blood stem cells were collected by means of apheresis with a continuous blood cell separator.

Patients underwent a median sternotomy with or without anterolateral thoracotomy within 6 weeks of completing induction chemotherapy. Total thymectomy with combined resection of the invaded surrounding tissue was carried out.

After full recovery from the operation, patients received HDCT consisting of carboplatin, ifosfamide, and etoposide. Carboplatin was administered at a dose of $400 \mathrm{mg} \cdot \mathrm{m}^{-2}$ on days $-7,-5$, and

\footnotetext{
From the Departments of Cancer and Thoracic Surgery and Hematology, Oncology and Respiratory Medicine, ${ }^{\mathrm{b}}$ Okayama University Graduate School of Medicine and Dentistry, Okayama, Japan

Received for publication May 9, 2005; revisions received May 12, 2005; accepted for publication June 7, 2005.

Address for reprints: Hiroshi Date, MD, Department of Cancer and Thoracic Surgery (Surgery II), Okayama University Graduate School of Medicine and Dentistry, 2-5-1 Shikata-Cho, Okayama 700-8558, Japan (E-mail: hdate@nigeka2.hospital.okayama-u.ac.jp).

J Thorac Cardiovasc Surg 2005;130:1205-6

$0022-5223 / \$ 30.00$

Copyright $\odot 2005$ by The American Association for Thoracic Surgery doi:10.1016/j.jtcvs.2005.06.006
}

-3 . Ifosfamide was administered at a dose of $3 \mathrm{~g} \cdot \mathrm{m}^{-2}$ on days -7 through -3 . Etoposide was administered at a dose of $500 \mathrm{mg} \cdot \mathrm{m}^{-2}$ on days $-7,-5$, and -3 . PBSCT containing peripheral blood stem cells $\left(3.6-11.2 \times 10^{6} \mathrm{CD} 34^{+}\right.$cells per kilogram) was performed 72 hours after completing HDCT (day 0) and just after administration of methylprednisolone $(250 \mathrm{mg})$. Granulocyte colony-stimulating factor was administered subcutaneously at a dose of $250 \mu \mathrm{g}$ beginning on day 1 and continued until an absolute neutrophil count of $\geq 1000 \mu \mathrm{L}$ was achieved.

\section{Results}

During the BEP induction chemotherapy, 2 patients had a partial response, and 1 patient had stable disease, as determined radiographically. AFP levels were decreased by BEP in all 3 patients but normalized only in 1 patient.

All 3 patients underwent radical intervention, with complete resections of the residual mediastinal tumors combined with invaded surrounding tissue. Pathologic diagnoses of the excised tumor were persistent NSGCT in 2 patients and teratoma in 1 patient. No perioperative complications were encountered. AFP levels became normal within 6 weeks after the operation in all 3 patients.

All 3 patients received HDCT supported by PBSCT 9 to 14 weeks after the operation without dose modification. As expected, all patients showed grade 4 neutropenia and thrombocytopenia.

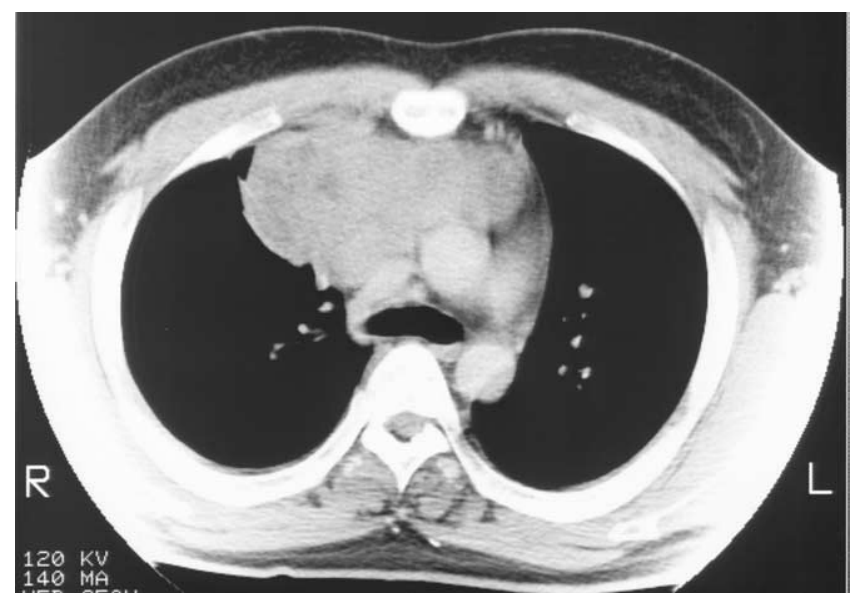

Figure 1. Chest computed tomographic scan showing a large anterior mediastinal tumor (patient 2). It was pathologically diagnosed as nonseminomatous germ-cell tumor by means of needle biopsy. 
TABLE 1. Characteristics of 3 patients with NSGCT of the mediastinum

\begin{tabular}{|c|c|c|c|}
\hline & Patient 1 & Patient 2 & Patient 3 \\
\hline Age (y) & 26 & 27 & 20 \\
\hline Sex & Male & Male & Male \\
\hline \multicolumn{4}{|l|}{ Tumor size $(\mathrm{cm})$} \\
\hline Pre-CT & $9.5 \times 7.2$ & $12.3 \times 7.5$ & $15.0 \times 9.0$ \\
\hline Post-CT & $4.5 \times 4.5$ & $11.0 \times 6.0$ & $4.0 \times 3.0$ \\
\hline Response & PR & SD & PR \\
\hline \multicolumn{4}{|l|}{ Surgery } \\
\hline Combined resection & Rt lung (partial) & $\begin{array}{l}\text { Pericardium } \\
\text { Lt BCV } \\
\text { Rt lung (partial) }\end{array}$ & Rt phrenic nerve \\
\hline \multicolumn{4}{|l|}{ Pathology } \\
\hline Pre-CT needle biopsy & NSGCT & NSGCT & NSGCT \\
\hline Excised tumor after CT & Teratoma & Persistent NSGCT & Persistent NSGCT \\
\hline \multicolumn{4}{|l|}{ AFP $(\mathrm{ng} / \mathrm{mL})$} \\
\hline Pre-CT & 1044 & 570.3 & 1180 \\
\hline Post-CT & 4.6 & 45.9 & 185.3 \\
\hline Pre-HDCT & 3.2 & 1.4 & 2.4 \\
\hline Current & 3.8 & 1.2 & 1.4 \\
\hline Outcome & 77 mo alive & 74 mo alive & 34 mo alive \\
\hline
\end{tabular}

$N S G C T$, Nonseminomatous germ-cell tumor; $A F P$, alpha-fetoprotein; $C T$, chemotherapy; $H D C T$, high-dose chemotherapy; $P R$, partial response; $S D$, stable disease; $B C V$, brachiocephalic vein.

They required platelet transfusions and supportive care for neutropenic fevers. Nonhematologic toxicity included grade 3 diarrhea in 1 patient, grade 2 alopecia in 3 patients, and grade 2 proteinuria in 2 patients.

They were discharged 16 to 17 days after PBSCT in excellent condition. They are currently alive 77, 74, and 34 months postoperatively, with no sign of recurrence.

\section{Discussion}

Although histologically and serologically identical to more common testicular counterparts, mediastinal NSGCT has a distinctly poorer prognosis. ${ }^{1}$ Recent studies have suggested that HDCT with autologous hematopoietic stem-cell support provides better survival than conventional dose chemotherapy for patients with relapsed or refractory testicular NSGCTs. ${ }^{2}$ However, HDCT has not been widely applied in patients with mediastinal NSGCTs. Takeda and associates ${ }^{3}$ used PBSCT to support HDCT in 2 patients with choriocarcinoma and 1 patient with embryonal cell carcinoma. These 3 patients were alive and disease free for 25 to 73 months.

Intensive platinum-based induction chemotherapy followed by surgical resection appears to be the current standard treatment for mediastinal NSGCT. An Indiana University group treated 79 patients with mediastinal NSGCTs with this strategy and reported an overall survival rate of $61 \%$ after an average follow-up of 48 months. ${ }^{4}$ The MD Anderson Cancer Center reported that the 2-year survival was $72 \%$ in 11 patients. ${ }^{5}$ In theses reports, oper- ations for patients whose markers had not normalized with induction chemotherapy was usually futile. It was also recognized that a pathologic finding of persistent viable NSGCT in the residual mass predicted the worst prognosis. Among the 3 patients in our study, 2 had increased AFP levels after induction chemotherapy and had pathologically persistent viable NSGCT in the residual tumor. Therefore we believe that HDCT with PBSCT played an important role in achieving long-term survival (77, 74, and 34 months) in our patients. Further investigations are warranted to clarify its effectiveness.

\section{References}

1. Dulmet EM, Macchiarini P, Suc B, Verley JM. Germ cell tumors of the mediastinum. A 30-year experience. Cancer. 1993;72:1894-901.

2. Beyer J, Stenning S, Gerl A, Fossa S, Siegert W. High-dose versus conventional-dose chemotherapy as first-salvage treatment in patients with non-seminomatous germ-cell tumors: a matched-pair analysis. Ann Oncol. 2002;13:599-605.

3. Takeda S, Miyoshi S, Ohta M, Minami M, Masaoka A, Matsuda H. Primary germ cell tumors in the mediastinum. A 50-year experience at a single Japanese institution. Cancer. 2002;97:367-76.

4. Kesler KA, Rieger KM, Ganjoo KN, Sharma M, Fineberg NS, Einhorn LH, et al. Primary mediastinal nonseminomatous germ cell tumors: the influence of postchemotherapy pathology on lung-term survival after surgery. J Thorac Cardiovasc Surg. 1999;118:692-701.

5. Walsh GL, Taylor GD, Nesbitt JC, Amato RJ. Intensive chemotherapy and radical resections for primary nonseminomatous mediastinal germ cell tumors. Ann Thorac Surg. 2000;69:337-44. 